\title{
O ESTADO BRASILEIRO PODE SER PROPRIETÁRIO E GESTOR DO SISTEMA FINANCEIRO?
}

COULD THE STATE BE BOTH OWNER AND MANAGER OF THE FINANCIAL SYSTEM? ¿EL ESTADO BRASILEÑO PUEDE SER PROPIETARIO Y GESTOR DEL
SISTEMA FINANCERO?

\section{Davi Augusto Santana de Lelis ${ }^{1}$}

\section{Giovani Clark ${ }^{2}$}

Licença CC BY:

Artigo distribuído sob os termos Creative Commons, permite uso e distribuição irrestrita em qualquer meio desde que o autor credite a fonte original.

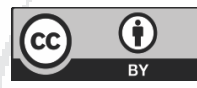

\begin{abstract}
Resumo: A crise financeira de 2008 possibilitou a elaboração de novas propostas, em todo o mundo, sobre o sistema financeiro. Nesse sentido, o presente texto examina se, no Brasil, pode-se aplicar a proposta teórica do jurista português Avelãs Nunes, com vistas a controlar as crises financeiras, de tornar o Estado único proprietário e gestor do sistema financeiro. Para verificar a viabilidade da proposta no estado brasileiro investiga-se se há, na Constituição de 1988, apenas uma ideologia determinante da racionalização normativa ou se há, no texto constitucional, múltiplas ideologias nacionalizantes de modo a ser possível acomodar a possibilidade de propriedade e gestão do sistema financeiro por parte do Estado brasileiro. Constatando a possibilidade jurídica, o ordenamento jurídico brasileiro é estudado com o intuito de se apontar o instituto jurídico capaz de instrumentalizar a tomada de propriedade do sistema financeiro pelo Estado brasileiro. Conclui-se que de acordo com a ideologia constitucionalmente adota (pluralismo ideológico) é possível a propriedade e gestão do sistema financeiro por via da encampação.
\end{abstract}

Palavras-chave: Sistema Financeiro; Constituição Econômica; Estatização; Encampação; Atividade Econômica.

Abstract: The 2008 financial crisis enabled new proposals to be drafted worldwide in relation to the financial system. This text examines whether the theoretical proposal of the Portuguese jurist Avelãs Nunes can be applied in Brazil to control financial crises, making the State the sole owner and manager of the financial system. To verify the feasibility of this proposal in the Brazilian state, it investigates whether, in the 1988 Constitution, there is only a determining ideology of the normative rationalization, or if the constitutional text contains multiple nationalizing ideologies that would allow for the possibility of ownership and management of the financial system by the Brazilian State. Having noted the legal possibility, the Brazilian legal system is studied, in order to point out the legal institute capable of instrumentalizing the ownership of the financial system by the Brazilian State. We conclude that according to the constitutionally adopted ideology (ideological pluralism), it is possible for the state to own and manage the financial system through expropriation. 
Keywords: Financial System; Economic Constitution; Neoliberalism; Expropriation; Economic activity.

Resumen: La crisis financiera de 2008 posibilitó la elaboración de nuevas propuestas, en todo el mundo, sobre el sistema financiero. En este sentido, el presente texto examina si, en Brasil, se puede aplicar la propuesta teórica del jurista portugués Avelãs Nunes, con vistas a controlar las crisis financieras, de convertir al Estado en el único propietario y gestor del sistema financiero. Para examinar la viabilidad de la propuesta en el estado brasileño se investiga si hay, en la Constitución de 1988, apenas una ideología determinante de la racionalización normativa o si hay, en el texto constitucional, múltiples ideologías nacionalizantes de modo a ser posible acomodar la posibilidad de propiedad y gestión del sistema financiero por parte del Estado brasileño. Constatando la posibilidad jurídica, el ordenamiento jurídico brasileño es estudiado con el intuito de apuntar el instituto jurídico capaz de instrumentalizar la toma de propiedad del sistema financiero por el Estado brasileño. Se concluye que de acuerdo con la ideología constitucionalmente adoptada (pluralismo ideológico) es posible la propiedad y gestión del sistema financiero por via de encampación.

Palabras clave: Sistema Financiero; Constitución Económica; Estatización; Encampación; Actividad Económica.

\section{INTRODUÇÃO}

Ao se pensar uma teoria do Estado, o arranjo institucional atual compreende a atuação estatal entre dois polos: o de concretização de direitos e o de atender às demandas do setor financeiro, conforme os ditames constitucionais. O equilíbrio entre os polos, desde a década de 1970, se "mantinha", em escala global, até a crise de 2008. Sobre essa crise, dentre os diversos diagnósticos, prevalece o que atribuiu o desencadeamento dos eventos à liberdade concedida ao setor financeiro privado. A referida liberdade só foi possível pela transformação do Estado de bem-estar social em um Estado Regulador e depois em Estado Garantidor e que adotam, simplificadamente, a seguinte cartilha: na teoria o Estado, em suas políticas econômicas, deve ser regulador e/ou garantidor do setor privado. Na prática há inversão da fórmula e se adota a liberdade de mercado como princípio organizador e regulador do Estado ${ }^{3}$. Entretanto, tais ideários, não afastam os riscos de ocorrência de novas crises financeiras.

Avelãs Nunes, jurista português, no artigo As duas últimas máscaras do Estado capitalista ${ }^{4}$ constrói uma crítica aos modelos reguladores e garantidores, apontando seus efeitos negativos na Europa. No mesmo texto, o autor lusitano propõe uma solução alternativa para as recorrentes crises financeiras visando solucionar o problema do controle do sistema financeiro sobre o aparelho do Estado. Para Avelãs Nunes, a propriedade integral e a gestão do sistema financeiro deveriam ser atribuições exclusivas do Estado.

3 FOUCAULT, Michael. Nascimento da Biopolítica. Martins Fontes: São Paulo, 2008, p. 158-159.

4 AVELÃS NUNES, António José. As duas últimas máscaras do Estado capitalista. Pensar. Fortaleza. v. 16, n. 2, p.409-476, jul/dez. 2011. 
A proposta de Avelãs Nunes, estabelecida no plano teórico jurídico, carece de ser constatada como possibilidade real. Deste modo o ensaio busca responder à seguinte questão: a solução apontada por Avelãs Nunes, a de que o Estado deve ser proprietário e gestor do sistema financeiro, é possível juridicamente no Brasil, sem ferir o Texto Constitucional de $1988^{5}$ ?

A fundamentação da resposta tem por itinerário a verificação da possibilidade jurídica, ou não, de a propriedade e gestão do sistema financeiro pelo Estado serem possíveis em face dos ditames da Constituição de 1988. Como método de análise adotamos o substancial analítico e a ideologia constitucionalmente adotada, filtro hermenêutico que permite afirmar os institutos econômicos oriundos de diversas ideologias foram refundados juridicamente na Constituição aferindo a legalidade e constitucionalidade antes das consequências materiais da política econômica analisada.

Para se alcançar o intento, o texto está dividido em três seções. Na primeira resgatamos o histórico da crise do Estado regulador e a emergência Estado garantidor. Na segunda, tratamos da estrutura jurídica econômica na Constituição de 1988. Na terceira verificamos qual o instrumento técnico-jurídico para o Estado brasileiro ter o controle e a gestão do sistema financeiro e, por fim, na conclusão, a discussão se encerra com o apanhado geral da análise e reflexões sobre as possibilidades futuras de pesquisa.

\section{DA CRISE DO ESTADO REGULADOR SURGE O ESTADO GARANTIDOR}

A Europa continental, após a segunda guerra mundial, optou por um modelo estatal que garantiria o bem-estar social. Entretanto, a partir de meados da década de 1970, o modelo foi contraditado e parcialmente desmontado. Nessa mudança estrutural nos interessa o financiamento público, que mantinha a economia nas rédeas do Estado e em prol da realização de direitos. A contestação do antigo arranjo foi o início da reação neoliberal de regulação ${ }^{6}$ possibilitada desde o desmonte do sistema Bretton Woods - acordo de 1944 sobre as relações financeiras entre as nações mais industrializadas. Tal sistema perdurou até 1971, quando os Estados Unidos, unilateralmente, decidiram acabar com a conversão do dólar em ouro; tornando-o moeda fiduciária de modo que o câmbio do dólar se tornasse "flutuante" e, portanto, à mercê do mercado e suas influências.

Com o fim do Bretton Woods e depois da guerra fria (1990), o sistema constitucional que sustentava o Estado Social passou a ser frontalmente atacado ${ }^{7}$. A téa década de 1970, com o instrumental keynesiano, garantia-se a ideia de que a expansão dos direitos sociais, empregos e barganha dos

5 O sistema financeiro é compreendido de acordo com a definição dada no art. 192 da Constituição de 1988 : "O sistema financeiro nacional, estruturado de forma a promover o desenvolvimento equilibrado do País e a servir aos interesses da coletividade, em todas as partes que o compõem, abrangendo as cooperativas de crédito, será regulado por leis complementares que disporão, inclusive, sobre a participação do capital estrangeiro nas instituições que o integram", deste modo estão inclusos na expressão os bancos públicos e privados, as instituições financeiras e as cooperativas de credito.

6 SOUZA, Washington Peluso Albino de. Primeiras Linhas de Direito Econômico. 6a edição. São Paulo: Editora LTr, $2^{\mathrm{a}}$ tiragem, 2017, p. 331.

7 BERCOVICI, Gilberto; MASSONETTO, Luís Fernando. A Constituição dirigente invertida: a blindagem da Constituição Financeira e a agonia da Constituição Económica. Boletim de Ciências Económica. Faculdade de Direito da Universidade de Coimbra, vol. XLIX, p.57-77, 2006, p.59. 
sindicatos era possível. Entretanto, com a crise do sistema, imposta por alta inflação, transpôs-se a dialética da inflação para a dívida pública e do investimento estatal para o endividamento privado ${ }^{8}$. Líderes políticos e estudiosos elaboram questionamentos, análises e estudos como subsídios ou propostas para alterações. François Mitterand, presidente francês na década de 1980 e combatente do Estado Social, considerou: ou se reconstruía a Europa ou se promovia a justiça social; pois o capitalismo não permite a prática de qualquer política social audaciosa9 .

No cenário de embate entre o Estado social e o Estado Regulador financeiro houve necessidade de se decidir, a partir de lutas de classes e interesses econômicos, entre os dois modelos: um buscava a promoção do bem-estar social; já o outro, o novo modelo regulador, afastava e reduzia o Estado da atividade socioeconômica e dos serviços públicos. Venceu o Estado Regulador financeiro, dando ênfase ao crescimento econômico, pois o "resto [supostamente] vem por si, não sendo necessárias quaisquer políticas activas para promover maior igualdade e maior justiça social"10.

Para garantir o crescimento econômico modernizante ${ }^{11}$ no lugar do desenvolvimento, seria necessário o Estado ficar restrito aos assuntos políticos e realizar minimamente a intervenção no domínio econômico e social. Se os orçamentos do Estado Social tinham por característica fundamental garantir os direitos e a prestação de serviços públicos à maioria da população, com a financeirização, a partir da década de 1970, o erário deixa de servir à execução de direitos fundamentais e passa a garantir a remuneração do próprio capital ${ }^{12}$. Para tal função - transformação de direitos em serviços -, as agências reguladoras ${ }^{13}$ seriam criadas, remodelas e instrumentalizadas a fim de regular a economia quando houvesse: a) falhas de mercado; b) desrespeito ao interesse público; c) necessidade de proteção aos consumidores ${ }^{14}$.

Portanto, de acordo com o seu marco fundamental, as agências reguladoras deveriam, em suas atuações, resguardar o interesse público e proteger o consumidor/cidadão. Mas a regulação tornou-se instrumento do poder econômico privado, pois os dirigentes das agências reguladoras, contrariando o cânone democrático, são, quase sempre, oriundos das próprias grandes empresas. Assim, a mão invisível da economia imaginada por Adam Smith tornou-se visível e passou a ter braços e corpos controlados pelo mercado ${ }^{15}$.

8 LELIS, Davi Augusto Santana de. Direitos sem dinheiro: do Novo Regime Fiscal à COVID-19. Ciências Sociais Unisinos. São Leopoldo. Vol. 56, N. 2. P. 164-176, maio/ago. 2020. p. 174.

9 AVELÃS NUNES, António José. As duas últimas máscaras do Estado capitalista, p. 419.

10 AVELÃS NUNES, António José. As duas últimas máscaras do Estado capitalista, p. 431.

11 BERCOVICI, Gilberto. Constituição econômica e desenvolvimento: uma leitura a partir da Constituição de 1988. São Paulo: Malheiros, 2005, p. 53.

12 BERCOVICl, Gilberto; MASSONETTO, Luís Fernando. A Constituição dirigente invertida: a blindagem da Constituição Financeira e a agonia da Constituição Económica, p. 68.

13 As agências reguladoras surgiram nos Estados Unidos da América, nos tempos de New Deal, década de 1930, e chegaram à Europa, via Reino Unido, um quarto de século depois, AVELÃS NUNES, António José. Breve reflexão sobre o chamado estado regulador. Revista Sequência. nº. 54, p. 9-18, jul. 2007, p. 13.

14 AVELÃS NUNES, António José. As duas últimas máscaras do Estado capitalista, p. 411.

15 AVELÃS NUNES, António José. As duas últimas máscaras do Estado capitalista, p. 421. 
Dessa liberdade descomedida ao setor privado, na "pandemia reguladora"16, acrescido da expansão financista nas relações estatais, resultou a crise de 2008. A crise, portanto, foi oriunda, em grande parte, do sistema financeiro privado que, em jogo de especulação perdeu grandes somas de dinheiro e foi socorrido uma vez mais pelo Estado. A Organização para a Cooperação e Desenvolvimento Econômico (OCDE) contabilizou que, após a crise de 2008, foram gastos U\$11,4 trilhões de dólares para salvar os bancos da bancarrota. O equivalente, à época, a U\$1. 676,00 por habitante do planeta ${ }^{17}$. No mesmo sentido, $\mathrm{Cruz}^{18}$, afirma: "Os países da Europa, que se esbaldaram jogando nesse cassino, afundam junto com a pretensa credibilidade e solidez do sistema financeiro dos Estados Unidos". Diante da crise, a Europa concluiu que o Estado regulador é um falso herói, pois é carente de transparência, é custoso e até mesmo impede o mercado de ser livre ${ }^{19}$, além de não possuir meios jurídicos e reais para deter/ limitar a força e o gigantismo do poder econômico financeiro.

Para solucionar os efeitos da crise de 2008, Canotilho ${ }^{20}$ propôs o Estado-ativo-tutelarsupervisionador-perceptor; ou, simplesmente, o Estado garantidor. Ao Estado garantidor não são reservadas grandes funções sociais; ele deve prestar serviços essenciais (principalmente via setor privado) e ser fiador dos serviços prestados pelas empresas. Avelãs Nunes ${ }^{21}$, aponta dificuldades no modelo proposto: a) não se sabe a responsabilidade do Estado, nem o que ele garante; b) há um hiato entre querer garantir a socialidade, confiada a serviços privados ou de gestão privada, e a execução efetiva desses serviços; c) o Estado garantidor assegura a saúde financeira das grandes empresas, encarregadas de prestar o serviço; d) os serviços essenciais podem passar a serviços de interesse geral; e) o Estado garante a situação de win-win, na qual o risco inexiste para o mercado; f) a responsabilidade, em vez de partilhada com o setor privado, é toda do Estado.

Em síntese, o Estado garantidor é um super-estado-feudal, que, em vez de os súditos pagarem pelo uso da terra, tem-se clientes pagando pelo uso de serviços. O teórico português acrescenta: "o estado tem apenas de garantir que estes serviços sejam colocados à disposição dos utentes (clientes). Que sejam empresas públicas (ou serviços públicos) ou empresas privadas a fazê-lo é, a esta luz, perfeitamente indiferente" 22 .

Silva e Pação, também portugueses, propõem um outro modelo onde se deve balancear "entre regras e princípios que o sistema se deve construir" ${ }^{\prime 23}$. A proposta é, no entanto, questionável, pois prevê um sistema que deve tipificar tudo, e, portanto, bastante rígido e distante das complexidades

16 CLARK, Giovani. O neoliberalismo de regulação como intervenção do Estado - A regulação e a Constituição de 1988. Lisboa: Lusíada: Economia \& Empresa, n. 9, 2009, p. 27.

17 AVELÃS NUNES, António José. As duas últimas máscaras do Estado capitalista, p. 469.

18 CRUZ, Paulo Márcio. A crise financeira mundial, o estado e a democracia econômica in Revista Pensar. Fortaleza. Disponível em: http://hp.unifor.br/pdfs_notitia/3364.pdf, acesso em 07 de maio de 2013, p. 01.

19 AVELÃS NUNES, António José. As duas últimas máscaras do Estado capitalista, p. 441.

20 CANOTILHO, J. J. Gomes. O Estado garantidor: claros-escuros de um conceito. In AVELÃS NUNES, António José; COUTINHO, J. N. Miranda (Org.). O Direito e o futuro: o futuro do direito. Coimbra: Almedina, 2008.

21 AVELÃS NUNES, António José. As duas últimas máscaras do Estado capitalista, p. 442.

22 AVELÃS NUNES, António José. As duas últimas máscaras do Estado capitalista, p. 445.

23 SILVA, Paula Costa; PAÇÃO, Jorge. A encruzilhada da supervisão das instituições de crédito. In Revista da Procuradoria-Geral do Banco Central. Volume 6. Número 2. dezembro de 2012. p.91-111. Brasília:BCB, 2012, p. 93. 


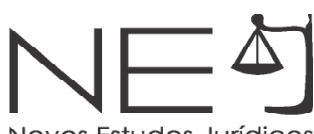

reais. A fórmula, porém, causaria desconfiança do mercado, sendo que a confiança é o pilar que o mantém. Nas palavras dos autores:

(...) é tempo de se dotar essa zona do ordenamento de regras claras, especialmente quando as matérias são particularmente sensíveis, regras que deverão ser editadas por um legislador, tanto quanto possível, não capturado e cuja aplicação efetiva seja controlada por autoridades com vastos, mas não ilimitados poderes ${ }^{24}$.

Ou seja, trata-se da remodelação da regulação (mais suave) para o estabelecimento de normas ou garantia de um funcionamento "equilibrado" do sistema financeiro ${ }^{25}$. A solução, de certa forma, também é apontada pelo Relatório Larosière ${ }^{26}$, onde se sugere deixar de proteger os pequenos credores e passar a controlar o risco sistêmico, evitando-se, assim, ameaças à estabilidade macroeconômica.

Para pôr em prática, na Europa, a ideia da regulação suave, criou-se o European Systemic Risk Board (ESRB), responsável pelo controle do mercado europeu ${ }^{27}$. Em Portugal, seguindo a tendência garantidora, reforçou-se a supervisão macroprudencial do Banco de Portugal ${ }^{28}$.

Distante das propostas amenas e pró-mercado, Avelãs Nunes, ao identificar que o problema tem origem no próprio sistema financeiro e que o modelo de Estado garantidor (Estado financeirizado) não solucionará a questão, apresenta uma solução de maior impacto, mas afigura a lógica anterior:

[...] deve caber ao estado a propriedade e a gestão do sistema financeiro, a gestão da poupança nacional, a definição das prioridades de investimento a realizar com ela, a responsabilidade pela 'produção' daquele bem público, chamando a si o controlo dos operadores financeiros, para acabar com os 'jogos de cassino' e para garantir que os operadores financeiros atuam sempre tendo apenas em vista o interesse público e não descure o 'seu papel de financiador das necessidades da economia real ${ }^{29}$.

É prudente lembrar, na contramão da proposta estatizante do setor financeiro de Avelãs Nunes, que o Brasil, apesar do pluralismo ideológico constante na Constituição, adotou-se, na prática, o

24 SILVA, Paula Costa; PAÇÃO, Jorge. A encruzilhada da supervisão das instituições de crédito, p. 109.

25 MOREIRA, Vital; MAÇÃS, Fernanda. Autoridades Reguladoras Independentes, estudo e projecto de leiquadro. Coimbra: Coimbra Editora, 2003.

26 LAROSIĖRE, Jacques de. et al. The High Level Group on Financial Supervisor in the EU. Bruxelas, 2009. Disponível em: http://ec.europa.eu/internal_market/finances/docs/de_larosiere_report_en.pdf, acesso em 10 de maio de 2013.

27 "The ESRB shall be responsible for the macro-prudential oversight of the financial system within the Union in order to contribute to the prevention or mitigation of systemic risks to financial stability in the Union that arise from developments within the financial system and taking into account macro-economic developments, so as to avoid periods of widespread financial distress. It shall contribute to the smooth functioning of the internal market and thereby ensure a sustainable contribution of the financial sector to economic growth." EUROPEAN SYSTEMIC RISK BOARD - ESRB. Mission, objectives and tasks. Disponível em: http://www.esrb.europa.eu/about/tasks/html/ index.en.html. Acesso em: 10 de maio de 2013.

28 SILVA, Paula Costa; PAÇÃO, Jorge. A encruzilhada da supervisão das instituições de crédito, 2012.

29 AVELÃS NUNES, António José. As duas últimas máscaras do Estado capitalista, p. 468-469. 
neoliberalismo de regulação ${ }^{30}$, que, na década de 1990, privatizou atividades econômicas estratégicas e serviços públicos (Intervenção estatal direta), e criou agências reguladoras modificando-se o padrão normativo pró-mercado (intervenção estatal indireta). Depois, entre 2003 e 2015, passou-se a outra faceta neoliberal reguladora redesenhada pelo neodesenvolvimentismo ${ }^{31}$, onde os investimentos em políticas públicas ampliaram-se e se preocupou com o mercado interno, mas sem abalar as estruturas reguladoras; e a partir de 2015 entrou na faceta do neoliberalismo de austeridade (Estado Garantidor de Canotilho), representado por: (i) radicalização das privatizações; (ii) ampliação das parcerias públicas e privadas; (iii) criação de novos marcos reguladores ainda mais favoráveis ao poder econômico privado; (iv) modificação da estrutura constitucional suspendendo-a por vinte anos, à partir de 2016, com a imposição do Novo Regime Fiscal - Emenda Constitucional n. 95 de 2016, que limita os investimentos públicos primários (saúde, educação, previdência, infraestrutura, pagamento de pessoal) mantendo livre apenas a possibilidade de pagamento de juros da dívida pública ${ }^{32}$.

A crise sistêmica do capitalismo ocidental e com consequências semelhantes, em face da Europa, também chegou ao Brasil que, como visto, já estrutura o seu próprio modelo de Estado Garantidor. Como consequência há ganhos pomposos e grande influência nas políticas econômicas públicas por parte do setor financeiro, em detrimento da concretude dos ditames do texto constitucional, tais como: da função social dos meios privados de produção e do capital, inclusive dos juros (art. 170, III da Constituição de 1988) e da promoção do desenvolvimento equilibrado da nação, servido o setor financeiro ao interesse coletivo (art. 192 da Constituição de 1988). Assim, diante da proposta de Avelãs Nunes, a fim de reverter o retrocesso nas políticas socioeconômicas, a primeira questão que aqui se discute é se seria possível, no Brasil, em face da Constituição de 1988, a propriedade e gestão do sistema financeiro por parte do Estado. A esse ponto dedica-se o próximo tópico.

\section{O ESTADO E A ATIVIDADE ECONÔMICA NO BRASIL DA CONSTITUIÇÃO DE 1988}

As constituições do século XX, em especial após as constituições do México de 1917 e de Weimar de 1919, abandonaram o aspecto exclusivamente político para contemplar também o aspecto econômico; por econômico entende-se a articulação entre o direito financeiro e o econômico de modo a realizar os direitos constitucionalmente previstos ${ }^{33}$. A separação do aspecto financeiro do aspecto econômico é que tornou possível, desde a década de 1970, a tensão entre o poder do Estado e a sociedade na organização do sistema capitalista, pois, desde então, ao se afastar do Direito Econômico, afastou-se também do Constitucional e do Estado de bem-estar social. A Constituição de

30 CLARK, Giovani. O pioneirismo da Faculdade de Direito da UFMG: a introdução do Direito Econômico no Brasil. Revista Brasileira de Estudos Políticos. Belo Horizonte. n. 40, ano 2012.

31 BOITO JR, Armando. BERRINGER, Tatiana. Classes Sociais, Neodesenvolvimentismo e Política Externa nos Governos Lula e Dilma. Revista de Sociologia e Política. v. 21, n. 47, set. 2013, p. 31-38, p. 31-35.

32 LELIS, Davi Augusto Santana de. Direitos sem dinheiro: do Novo Regime Fiscal à COVID-19, p. 170.

33 BERCOVICl, Gilberto; MASSONETTO, Luís Fernando. A Constituição dirigente invertida: a blindagem da Constituição Financeira e a agonia da Constituição Económica, p. 58. 
1988, todavia com uma cisão aparente entre o financeiro e o econômico, prevê em seu Título VII, Da Ordem Econômica e Financeira, o conjunto de artigos que se denominam Constituição Econômica.

Para avaliar se a proposta de Avelãs Nunes é viável no Brasil, antes da verificação da literalidade dos artigos do Título VII da Constituição de 1988, faz-se necessário saber se a Constituição comporta alguma ideologia determinante. Caso a Constituição de 1988 contemple exclusivamente a ideologia capitalista/liberal, o fundamento da proposta de Avelãs Nunes é, por razão fundamental, inviável no Brasil. De modo a avançar na proposta faz-se necessário esclarecer o que se entende por ideologia.

Ideologia, segundo Ricouer ${ }^{34}$, possui três funções. A primeira delas é o de mito fundador de uma dada sociedade. Assim, a ideologia se apresenta como estrutura de motivação social que se perpetua no tempo e no espaço. Por exemplo, se a Constituição de 1988 adotasse o liberalismo ${ }^{35}$ como mito fundador da sociedade brasileira, seria apenas essa a ideologia a ser reproduzida em seu texto. A ideologia também possui a função de dominação, pois no aspecto temporal o novo só é concebido socialmente a partir do que é típico, do que se encontra assentado como mito inicial da sociedade. Deste modo, a modificação na estrutura financeira da nação brasileira só seria possível se o que está tipificado no texto constitucional permitisse uma estrutura em que o Estado se torne, constitucionalmente proprietário e gestor do sistema financeiro. A terceira e última função de ideologia, identificada por Ricouer, tem cunho marxista e se apresenta como deformação da realidade. Deste modo, na luta de classes, se os operários não tomam consciência de sua posição subalterna na sociedade, hão de agir em conformidade com as diretrizes sociais e ideológicas de elite financeira, acreditando na ilusão de que um dia poderão ocupar as posições de cima da escala social. Adorno, Horkheimer, Marcuse e Habermas perceberam que, em determinada fase da história, a ciência também funcionava como ideologia ${ }^{36}$ e inclusive a grande maioria dos intelectuais atuam como realizadores da violência simbólica ${ }^{37}$ em prol do capital. Assim, teorias econômicas oriundas da ideologia neoliberal, sejam elas de opção pela regulação ou pela austeridade, buscam justificar as alterações legislativas em prol de um Estado financeirizado em detrimento de um Estado realizador de direitos fundamentais.

A tomada de decisão ideológica faz parte da construção teórica da Constituição; pois, para criar o texto constitucional, existiriam disputas humanas a partir dos modelos puros de ideologia, construindo a pluralidade dos ditames constitucionais a serem depurados/harmonizados pelo princípio

34 RICOUER, Paul. Interpretação e ideologia. 4ª ed. Rio de Janeiro: Francisco Alves. 1990, p. 71.

35 Sabemos ser, no mínimo questionável, a afirmação de que há, no Brasil um liberalismo à moda de Tocqueville e Carpeaux. O pensamento político e a mentalidade de nossas elites fundadoras sofreram, desde a independência e consolidação da nação brasileira modificações que impediram, entre nós o florescimento de um verdadeiro pensamento liberal. O liberalismo que por aqui prevaleceu sacrificou a identidade original e, em nome de uma suposta modernização, elegeu a tradição política até então vigente como a herança a ser eliminada. Nessa perspectiva seria possível falar, sem qualquer absurdo, do liberalismo-conservador brasileiro. Entretanto, não sendo este o objetivo do presente ensaio.

36 RICOUER, Paul. Interpretação e ideologia, p. 75.

37 SOUZA, Jessé. A tolice da inteligência brasileira: ou como o país se deixa manipular pela elite. São Paulo, Leya, 2015, p. 10. 
da ambiguidade ${ }^{38}$. O princípio condiciona as estruturas sociais, políticas e econômicas à ordem jurídica. Assim, as ordens econômicas e financeiras constitucionais (comandos), oriundas do pensamento de diversas ideologias, existentes e conflitantes durantes a construção das constituições modernas, nas assembleias constituintes, ficam submetidas ao que está previsto no texto constitucional, evitandose, assim, a dominação e a distorção social por meio de ideologias puras.

Sabe-se que na ação social weberiana o comportamento coletivo é significante para o comportamento individual quand o a ação ou omissão de um é orientado em função do comportamento do outro. O entendimento aproxima-se da construção da ideia de bolha de sabão ${ }^{39}$ que explica a existência de uma ordem ambígua na sociedade. Essa ordem ambígua é construída, portanto, por grupos sociais antagônicos que precisam se representar em sociedade. Tal representação social é construída em comunidade histórica com o ato fundador. Assim, há uma difusão da convicção inicial formadora daquela dada sociedade por meio de um credo. Ricoeur explica que "talvez não haja grupo social sem essa relação indireta com seu próprio advento"40.

Não é intenção, neste ensaio, aprofundar essa discussão, apenas ressalta-se que as três funções da ideologia de Ricouer não constituem conceitos antagônicos e que todos eles constituem a ideologia constitucional a que aqui se faz menção. Portanto, a ideologia constitucional é, em uma interpretação atual da teoria de Washington Peluso Albino de Souza ${ }^{41}$, a soma das funções estabelecidas por Ricouer. Ideologia, nesta linha de pensamento, é uma racionalização que constitui anteparo do real; de modo que as ações sociais dependem de relações estáveis e com significações que possam ser compreendidas facilmente pela sociedade. Trata-se, portanto, da impossibilidade de se construir uma teoria social ou texto normativo não-ideológicos, pois é a repetição do momento fundador inicial, promovendo a mobilização e a justificativa social. A ideologia (pura) é, pois, uma estrutura de pensamento vinculada a um grupo, a uma classe social, a uma nação, de modo que as construções ideológicas, assim erigidas, não passam de mito ou de estereótipos que se propõem de maneira enviesada e totalizante.

As teorias deste modo ideológico são as que Souza ${ }^{42}$ denominou de puras: ideologias que contém elementos indispensáveis à construção de suas racionalidades. Inserem-se nessa categoria, por exemplo, o liberalismo, o socialismo, o comunismo, o nacionalismo. A par delas, existem também ideologias denominadas mistas que recebem, por exemplo, o prefixo neo; designando o sentido mesclado de princípios ideológicos e as mutações decorrentes do percurso temporal. As ideologias mistas, quando aplicadas à realidade, podem não significar funções de ideias e sim alterações não

38 SOUZA, Washington Peluso Albino de. O princípio da ambiguidade na configuração legal da ordem 'econômica'. Revista da Faculdade de Direito da UFMG, n.21(13), 1956.

39 SOUZA, Washington Peluso Albino de. O princípio da ambiguidade na configuração legal da ordem 'econômica', 1956.

40 RICOUER, Paul. Interpretação e ideologia, p. 68.

41 SOUZA, Washington Peluso Albino de. Primeiras Linhas de Direito Econômico, 2017.

42 SOUZA, Washington Peluso Albino de. Conflitos Ideológicos na Constituição Econômica. Revista Brasileira de Estudos Políticos. Belo Horizonte, Universidade Federal de Minas Gerais n. 74-75, jan-jul. 1992, p. 23. 
substanciais no plano de concepção original significando, por vezes, a sua radicalização como ocorre, por exemplo, com o neoliberalismo de regulação e de austeridade ${ }^{43}$. Nessa categoria também estão, por exemplo, o anarcocapitalismo e o neosocialismo. À vista disso, as teorias mistas precisam ser depuradas/harmonizas por um filtro hermenêutico constitucional, evitando-se, assim, que a constituição se componha de termos contraditórios, dominadores e deformadores das ações sociais e estatais. Ademais, foram diversos os atores sociais que influenciaram e participaram da construção da constituição e, logicamente, diversos grupos inseriram suas ideologias no texto no constitucional.

Souza44, ao interpretar a constituição econômica, pretendendo "livrar" o texto constitucional da influência exclusiva das ideologias puras, desenvolveu a ideia de ideologia constitucionalmente adotada. Esse é o projeto estabelecido na Constituição de 1988: ideologias que representam distâncias, discordâncias, concordâncias e ambiguidades referentes ao curso real das coisas; tendo, na ideologia constitucionalmente adotada, o filtro hermenêutico que depura as escolhas dos agentes estatais e faz com que o discurso puramente financista passe pelo crivo constitucional antes de ser concretizado.

Note-se que a Constituição de 1988 não é, de forma alguma, neutra ${ }^{45}$. Ela tem, na verdade, corpo normativo com natureza instrumental e transformador das estruturas econômicas, sociais, tecnológicas, ambientais, e a ideologia constitucionalmente adotada atua como filtro hermenêutico para justificar as escolhas de políticas econômicas ${ }^{46}$. Em se tratando da ordem econômica, nenhum fenômeno econômico depende do direito, mas a ordem econômica moderna não pode existir sem uma ordem jurídica.

Observa-se, assim, que não há na Constituição de 1988 uma ideologia determinante (pura) que impeça a execução da proposta de Avelãs Nunes no Brasil. O que há na Constituição de 1988 são dispositivos ambíguos, frutos de diversas ideologias que devem ser harmonizados por meio do filtro hermenêutico denominado ideologia constitucionalmente adotada. Há, então, amplitude de possibilidades nas ações estatais e não apenas a ação financeira privada de suposição racional e neutra. Trata-se, portanto, da busca pela concretude constitucional em seu aspecto ético: luta pela realização de direitos fundamentais.

Entretanto, com a crescente financeirização do Estado, identificada por Avelãs Nunes como máscaras que tentam, em vão, disfarçar o Estado capitalista, a complexidade constitucional da ambiguidade e a depuração pela ideologia constitucionalmente adotada deixam de existir. Sem o crivo da ideologia constitucionalmente adotada passa-se a vigorar uma única ideologia política/ econômica: a oriunda do neoliberalismo. As consequências deste movimento de unificação ideológica

43 CLARK, Giovani. CORREAA, Leonardo Alves. NASCIMENTO, Samuel Pontes do. A Constituição Econômica entre a Efetivação e os Bloqueios Institucionais. Revista da Faculdade de Direito da Universidade Federal de Minas Gerais, n, 71, jul/dez 2017, p. 677-700.

44 SOUZA, Washington Peluso Albino de. Teoria da Constituição Econômica. Belo Horizonte: Del Rey, 2002.

45 BELTRÁN, Enrique Navarro. La Constitución Económica Chilena Ante Los Tribunales de Justicia. Providencia: Universidad Finis Terrae, 2016, p. 31.

46 CLARK, Giovani. CORRÊA, Leonardo Alves. NASCIMENTO, Samuel Pontes do. A Constituição Econômica entre a Efetivação e os Bloqueios Institucionais, p. 280. 
são, na lição de Salgado ${ }^{47}$ : (a) corrupção da república, que deveria ter a legitimação do poder estatal relacionada com sua origem e finalidade para com a realização de direitos fundamentais; (b) o aumento do poder burotecnocrata e redução do poder político e social e; (c) mudanças constantes do texto constitucional para acomodar os interesses ideológico neoliberais (reguladores ou de austeridade) em detrimento dos direitos e garantias fundamentais.

A essa unificação ideológica, Bercovici e Massonetto ${ }^{48}$ denominaram de constituição dirigente invertida: a constituição dirigente - a que realiza os direitos sociais e políticas públicas de interesse à nação passa a ser vista como prejudicial e causadora das crises econômicas, do déficit público e da ingovernabilidade. Já constituição dirigente invertida, em contrapartida, é a execução de políticas neoliberais de ajuste fiscal, voltadas ás credibilidade e confiabilidade da nação junto ao sistema financeiro internacional.

Acentua-se mais uma vez que o texto constitucional de 1988, escrito após a crise dos anos 1970, influenciado pelos princípios keynesianos e pelas experiências estruturalistas, apresenta conteúdo ambíguo que pretende realizar tanto o Estado de bem-estar social quanto, supostamente, o Estado financeiro. Isto porque no texto constitucional existem normas que possibilitam a defesa teórica do equilíbrio das contas públicas em detrimento da atuação estatal que se denomina ética e realizadora dos direitos fundamentais.

Esses argumentos são sintetizados por Souza ${ }^{49}$ no entendimento de que a ordem econômica de cunho liberal tem como fundamento a livre iniciativa; e como princípios, a propriedade privada e a livre concorrência. Paralelamente, a ordem econômica de cunho social tem como fundamento a valorização do trabalho humano, a existência digna e; princípios como: a soberania econômica nacional, a função social da propriedade dos meios de produção e do capital, a proteção do meio ambiente, a redução das desigualdades regionais e sociais e a busca do pleno emprego. Sobre esse conjunto de ideias e comandos, aparentemente antagônicos, há uma soma que cria um modelo ideológico misto, orientado por uma linha de maior vantagem, devendo gerar uma interpretação mais justa ou recomendável mediante a circunstancialidade apresentada.

Tem-se, portanto, o termo de que não há na Constituição de 1988 uma ideologia pura, determinante e sim dispositivos frutos de diversas ideologias, devendo ser harmonizados por meio de uma interpretação mais justa em face da realidade brasileira. Também há uma admissão do sistema capitalista, bem com como de outros sistemas produtivos compatíveis ${ }^{50}$ que devem ser, a todo tempo, limitados e moldados aos ditames e objetivos constitucionais a fim garantir justiça

47 SALGADO, Joaquim Carlos. O Estado ético e o Estado poiético. Revista do Tribunal de Contas de Minas Gerais, Belo Horizonte, v.27, n.2, abr/jun, 1998, p. 8-10.

48 BERCOVICI, Gilberto; MASSONETTO, Luís Fernando. A Constituição dirigente invertida: a blindagem da Constituição Financeira e a agonia da Constituição Económica, p. 73.

49 SOUZA, Washington Peluso Albino de. Teoria da Constituição Econômica. Belo Horizonte: Del Rey, 2002, p. 372.

50 CLARK, Giovani; CÔRREA, Leonardo Alves; NASCIMENTO, Samuel Pontes do. Ideologia constitucional e pluralismo produtivo. Revista da Faculdade de Direito da UFMG: número especial em memória do Professor Washington Peluso Albino de Souza, ano 2013, p. 292. 
social e mais bem-estar para todos ${ }^{51}$. Assim, do ponto de vista da ideologia constitucional e de seus ditames, pode-se afirmar que é possível o controle e a propriedade do sistema financeiro por parte do Estado, enquanto setor econômico estratégico e essencial, visando a concretude da Lei Maior. Exemplificando: na efetivação da soberania econômica nacional (art. 170, I da Constituição), quando o mercado interno, por compor o patrimônio nacional (art. 219 da Constituição), for colocado em risco ou fragilizado por suas ações e omissões privadas; ou ainda, para assegurar a função social da propriedade (capital financeiro e juros), bem como para garantir a livre concorrência e da defesa do consumidor (art. 170, III, IV, V da Constituição) findando-se os abusos do poder econômico dos bancos (art. 173, parágrafo 4 da Constituição), entre outros.

Subsidia a resposta à primeira questão a verificação da literalidade dos artigos da Constituição de 1988, conferindo a possibilidade da aplicação da proposta de Avelãs Nunes no Brasil.

Sabe-se que não há serviço público econômico no Brasil, pois, na Constituição de 1988, estas expressões têm tratamentos antinômicos ${ }^{52}$ : ou se tem serviço público ou se tem atividade econômica em sentido estrito ${ }^{53}$. Com base nessa afirmação, sabe-se que o sistema financeiro não presta um serviço público nos termos do artigo 175 da Constituição de 1988 ou, caso assim fosse, o Estado deveria credenciar o particular prestador do serviço, por meio de uma concessão ou permissão, o que não tiraria do Estado a titularidade do serviço ${ }^{54}$.

O artigo 173 da Constituição de 1988, que trata das atividades econômicas, dispõe, com limites, os casos previstos em que a exploração direta de atividade econômica pelo Estado será permitida. A atividade econômica estatal pode ocorrer quando for necessária aos imperativos de segurança nacional ou relevante interesse coletivo, conforme definido em lei. Bandeira de Mello ${ }^{55}$ aponta como ressalvas constitucionais as previstas no artigo 177, monopólio da União, as atividades econômicas não sujeitas aos limites do artigo 173: a pesquisa e lavra das jazidas de petróleo e gás natural e outros hidrocarbonetos fluídos; a refinação do petróleo nacional ou estrangeiro; importação ou exportação dos produtos e derivados de petróleo, gás natural ou outros hidrocarbonetos fluídos e; o transporte marítimo ou por meio de conduto do petróleo bruto, seus derivados e gás natural.

51 Há pensamento jurídico em sentido contrário; no qual, a livre iniciativa é o direito fundamental que condiciona os demais, pois a livre iniciativa é sinônimo de iniciativa econômica privada. Neste sentido, entende-se que a livre iniciativa garante a realização de qualquer atividade, estando o setor privado protegido pela legislação. Discordase desses pensamentos, pois eles tornam a livre iniciativa oriunda de uma ideologia mista, a neoliberal, em um princípio inviolável; o que é inaceitável do ponto de vista constitucional.

52 BANDEIRA DE MELLO, Celso Antônio. Curso de Direito Administrativo. 26a ed. Editora Malheiros: São Paulo. 2009, p. 789.

53 GRAU, Eros Roberto. A ordem econômica na constituição de 1988. 14. ed. São Paulo: Malheiros, 2010, p. 101102.

54 BANDEIRA DE MELLO, Celso Antônio. Curso de Direito Administrativo, p. 788.

55 BANDEIRA DE MELLO, Celso Antônio. Curso de Direito Administrativo, p. 788. 
A interpretação constitucional é a de que o Estado pode desenvolver atividade econômica obedecendo os pressupostos citados e mediante autorização legislativa. Aliás, Silva ${ }^{56}$ e Bercovici ${ }^{57}$ reforçam esta linha de raciocino jurídico e deixam claro que o Estado não limita a intervenção direta do domínio econômico às formas subsidiária, suplementar e excepcional, mas sim aos contornos constitucionais, possuindo, ainda, o poder/dever de assim agir em nome da materialização da constituição de 1988.

O artigo 173 da Constituição de 1988 contribui na resposta à questão proposta. Na literalidade do artigo há possibilidade de o Estado prover atividade econômica por relevante interesse coletivo ${ }^{58}$. A expressão comporta interpretações. Defende-se, neste ensaio, a ideia de que o relevante interesse coletivo, expressão sem densidade conceitual, nada mais é que espécie do gênero interesse público. Em conformidade com esta proposta, $\mathrm{Grau}^{59}$ afirma que os interesses coletivos são aferidos no plano da sociedade civil e, embora sejam distintos do interesse social, ambos (interesse coletivo e interesse social) se componham na categoria de interesse público.

Por interesse público entende-se a efetivação da própria constituição, em especial os direitos e garantias fundamentais ${ }^{60}$. Note-se que o interesse público não se confunde com o interesse privado, pois resultaria em uma soma dissonante de interesses e direitos contraditórios; não se confunde também com o interesse comum a todos os cidadãos: vivemos em sociedade repleta de individualidades não permitindo a totalização em torno de apenas um interesse. Não havendo homogeneidade não há, também, que se falar que o interesse público é o que atende ao critério da maioria. Na realização dos direitos fundamentais, os direitos das minorias também devem ser levados em consideração. Por isto é que se pode afirmar que o núcleo dos interesses públicos são os direitos fundamentais - incluindo os direitos sociais -, elencados na Constituição de 1988. O que se pretende na delimitação do interesse público é dar concretude e definição jurídica que possibilite a concretização do texto constitucional ${ }^{61}$.

De acordo com o magistério de Magalhães ${ }^{62}$, desde a Constituição do México de 1917 e de Weimar de 1919, os direitos econômicos passaram ao patamar de direitos fundamentais; carecendo, assim, de maior proteção. Deste modo, entre o interesse privado - financeirização do Estado - e o interesse público - de concretização ética da Constituição de 1988 - este último deve prevalecer. Sendo os interesses públicos direitos e garantias fundamentais (compreendendo entre eles os direitos econômicos) previstos primariamente na Constituição de 1988 e que se destinam a assegurar

56 SILVA, José Afonso da. Comentário Contextual à Constituição. $6^{\circ}$ edição. São Paulo: Malheiros, 2009, p. 177.

57 BERCOVICI, Gilberto. Constituição econômica e desenvolvimento: uma leitura a partir da Constituição de 1988. São Paulo: Malheiros, 2005, p. 35.

58 BRASIL, Constituição da República Federativa do Brasil de 1988. Disponível em: http://www.planalto.gov.br/ ccivil_03/constituicao/constituicao.htm. Acesso em 06 de maio de 2013.

59 GRAŪ, Eros Roberto. A ordem econômica na constituição de 1988, p. 129.

60 USTEN FILHO, Marçal. Curso de Direito Administrativo. Ed. Saraiva. São Paulo. 2005, p. 35.

61 LELIS, Davi Augusto Santana de. Ensaios sobre a atuação estatal. Rio de Janeiro: Lumen Juris. 2019 , p.118.

62 MAGALHÃES, José Luiz Quadros. Direito Constitucional: curso de direitos fundamentais. $3^{a}$ ed. São Paulo: Método. 2008, p. 22. 


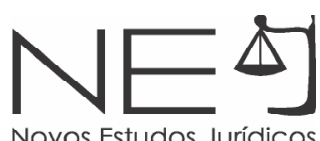

a dignidade humana em suas diversas manifestações de projetos de vida boa, deve-se, com força na ideologia constitucionalmente adotada, fazer prevalecer a melhor interpretação ideológica que concretize tais direitos ${ }^{63}$.

Sumarizando, a crise de 2008, força motora para a proposta de Avelãs Nunes, foi provocada especialmente pelos interesses financeiros privados, que conseguiram, nos Estado Unidos e na Europa, crescente desregulação das operações financeiras. Acredita-se que seria possível, ainda que teoricamente, evitar consequências outras no Brasil, com a defesa do relevante interesse coletivo interesse público -, autorizando a propriedade e controle do sistema financeiro por parte do Estado.

Assim, pela constatação de ausência de uma ideologia pura dominante, somada a literalidade dos artigos 170, 173, 174 e 219 da Constituição de 1988 e com a interpretação de que os direitos econômicos são parte constitutiva do interesse público (concretização ética da Constituição), afirmamos ser possível o Estado brasileiro, para vistas a defender o interesse o público, tomar a propriedade e controle do sistema financeiro nacional. Validada, assim, a primeira hipótese: a propriedade e gestão do sistema financeiro pelo Estado são possíveis sob as normas da Constituição de 1988.

Busca-se agora responder a seguinte questão: existe mecanismo jurídico capaz de instrumentalizar o Estado para a propriedade e gestão do sistema financeiro? A esse tema dedica-se a próxima sessão.

\section{O INSTITUTO PARA A PROPRIEDADE E GESTÃO DO SISTEMA} FINANCEIRO

A Constituição de 1988 legitima o Estado brasileiro para intervenção no domínio econômico, de modo direto (artigo 173, caput da Constituição) e indireto (artigo 174 da Constituição), bem como a possibilidade de desapropriação realizada pelo Estado dos bens e ativos privados (artigo $5^{\circ}$, XXIV da Constituição). Por conseguinte, para uma eventual propriedade e gestão do sistema financeiro, resta saber se há instrumento jurídico no ordenamento nacional que legitime tal medida. A resposta à questão deve construir-se com base nos próprios artigos constitucionais.

Como exemplos de retomada estatal em conformidade com a Constituição, identificam-se duas situações em nações onde é preponderante o modelo de produção via meios privados: na Bolívia, para evitar a concentração e exploração indevida da propriedade e; a tendência britânica de estatização de diversos serviços de interesse público. Sobre a lei boliviana, eis o problema jurídico: em 2013 o presidente boliviano, atendendo à demanda popular de remarcação de terras, questionou a constitucionalidade do projeto de lei denominado Ley de Extinción de Dominio de Bienes a Favor del Estado. No referido projeto de lei pretendia-se reverter bens privados, que não atendiam à função social da propriedade por motivos diversos como crime organizado, lavagem de dinheiro, tráfico de pessoas, enriquecimento ilícito, entre outras, para o domínio do Estado sem a realização do devido

63 LELIS, Davi Augusto Santana de. Ensaios sobre a atuação estatal, p. 119. 
processo legal. O tribunal, em análise do projeto entendeu ${ }^{64}$ que a constituição boliviana obriga os proprietários privados ao cumprimento dos requisitos constitucionais e legais de manter a licitude e a função social da propriedade. Contudo, sem a licitude e sem a função social, a propriedade estaria desprotegida do arcabouço constitucional boliviano podendo, portanto, ser revertida ao patrimônio público, desde que seja obedecido o devido processo legal ${ }^{65}$. Nessa situação, além do respeito ao direito posto, houve respeito ao critério democrático, visto que as medidas de intervenção do Estado na economia se pautaram sempre no apoio e demanda popular.

Modelos alternativos ao modelo tradicional de concessão de serviços públicos e atividades econômicas têm sido implementados também na Inglaterra. Trata-se do Social Impact Investment Markets (SIIM), modelo adotado pelos ingleses desde 1997, envolvendo o capital privado em atividades sociais que possam gerar retorno financeiro para os investidores; e o Social Impact Bond (SIB), que surge como resposta à crise de 2008. Quanto ao SIIM, pode-se identificar três formas de implementação: (i) redução da tributação em determinadas áreas para incentivar o investimento privado; (ii) empréstimo de recursos públicos, em especial para o terceiro setor, para a realização de investimentos sociais e; (iii) uso de capital privado para expandir o investimento social ${ }^{66}$.

O último modelo de SIIM, uso de capital privado para expansão do investimento social, é, na prática, o modelo pela qual se estrutura o SIB: diferente do tradicional contrato de concessão de serviços públicos, o SIB é remunerado por investidores privados tendo por base a performance do serviço prestado: o investidor ganha um prêmio por cada resultado positivo que alcança - o resultado pode ser, desde realização de metas, como educar um determinado número de crianças, quanto gerar economia para os cofres públicos. Se a atividade não alcança a meta pré-estabelecida, o investidor perde o dinheiro investido e não recebe o prêmio ${ }^{67}$.

Ademais, o SIB deverá ter previsto em seu instrumento constitutivo que seu objetivo é a prestação do benefício público ao qual a lucratividade está vinculada. Por exemplo: a empresa que presta o serviço de água teria como propósito entregar ao consumidor a melhor água pelo menor preço. Além disso, a empresa de benefícios públicos seria gerida em parte por uma fundação pública com participação do governo via nomeação de administradores não executivos; e em parte por capital privado aberto ao mercado. Aos administradores não executivos caberia a responsabilidade de verificar se o propósito para o qual a empresa de benefícios públicos foi criada está sendo cumprido. Ao capital privado caberia o investimento necessário para execução do objetivo da empresa de benefícios públicos e, eventualmente, o recebimento de lucros e dividendos. Entre as duas pontas,

64 OLÍVIA. Declaración Constitucional Plurinacional 02/2013, 19 de abril de 2013. Diposnível em: http://www. tcpbolivia.bo/tcp/content/declaraci\%C3\%B3n-constitucional-plurinacional-022013-19-de-abril-de-2013. Acesso em 18 de abril de 2018.

65 BOLÍVIA. Declaración Constitucional Plurinacional 02/2013, 19 de abril de 2013.

66 WIGGAN, Jay. Policy Boostering the Social Impact Investment Market in the UK. Jnl Soc. Pol. Cambridge University Press. Vol. 47, no 4, p. 721-738. 2018.

67 DOWLING, Emma. After Austerity: Social Impact Bonds and the financialisation of the welfare state in Britain. New Politcal Economy. Setember, 2016. 
a pública e a privada, mantém-se o sistema regulador já em vigência na Inglaterra ${ }^{68}$. Se a empresa de benefícios públicos não entrega o que foi prometido, passa-se a aplicar o sistema de penas escalonadas culminando com a mais grave: a transformação de todos os bens em propriedade pública. A desapropriação dos bens particulares teria custo menor que a indenização prevista para a encampação, pois, a empresa de benefícios públicos, ao não entregar o prometido, passa a atuar em ilegalidade, causando uma queda em suas ações privadas e, consequentemente, menor dispêndio para o Estado que deverá arcar somente com o valor de mercado da empresa.

Sobre a viabilidade do SIB, Hutton ${ }^{69}$, informa que o modelo se pauta no crescente descontentamento entre os consumidores com relação a serviços públicos fornecidos por empresas privadas. Além de supostamente condicionar a prestação do serviço público à satisfação social, o SIB apresenta como pontos positivos: (i) a possibilidade de se evitar/reduzir indenização em caso de eventual estatização e; (ii) a separação do serviço social do fundo financeiro, permitindo que o setor privado lucre com a prestação do serviço enquanto retira o risco da atividade das mãos do Estado.

Apesar dos aspectos supostamente positivos, a visão predominante destes modelos é neoliberal de regulação e de austeridade. Afinal, para qualquer um deles, (SIIM ou SIB), o bem-estar social é apenas um custo para o Estado. Por outro lado, o SIB, em especial, proporciona uma financeirização do Estado em áreas até então impenetráveis pelo capital especulativo. O capital em crise, em especial após 2008, precisou ser criativo para encontrar novas áreas de exploração. Os novos modelos de administração de serviços público demonstram o Estado gerencial se renova na marcha de esvaziar os entes púbicos de seu dever de efetivar direitos. Caso se opte, no Brasil, por um dos modelos acima, consolidando o neocolonialismo jurídico, é preciso modificação constitucional, pois, para o setor econômico, a Constituição de 1988 afirma ser necessária a constituição de empresa pública ou sociedade de economia mista. Assim, a forma de organização administrativa, SIIM ou SIB, precisariam ser incluídas na Constituição de 1988 com todas as especificações que, por ventura, permitiriam ao Estado a tomada do serviço econômico. Contudo, a proposta em análise no artigo (estatização do setor financeiro) independe da alteração constitucional, tornando-se imperioso saber como a Constituição de 1988 estabelece os limites entre os espaços público e privado dentro da atividade econômica e as possíveis formas de intervenção do Estado no domínio econômico.

Grau $^{70}$ trata as formas de intervenção do Estado na economia da seguinte maneira: o Estado poderia: (i) intervir diretamente por meio da absorção, assumindo integralmente o controle dos meios de produção e atuando em regime de monopólio ou; por meio da participação, controlando parte dos meios de produção e atuando em regime de competição com o mercado; (ii) intervir indiretamente por meio da direção, exercendo pressão sobre a economia por meio de normas de comportamento compulsório ou; por indução, manipulando os instrumentos de intervenção de acordo com as leis que regem o mercado. Ademais, Grau ${ }^{71}$ utiliza o termo intervenção quando o Estado age em campos

68 HUTTON, Will. Podemos desfazer a privatização. E não nos custará um centavo. Disponível em: https:// jornalggn.com.br/noticia/britanicos-querem-reestatizar-empresas. Acesso em 10 de março de 2018.

69 HUTTON, Will. Podemos desfazer a privatização. E não nos custará um centavo.

70 GRAU, Eros Roberto. A ordem econômica na constituição de 1988, p. 147.

71 GRAU, Eros Roberto. A ordem econômica na constituição de 1988, p. 91. 
inicialmente pertinentes ao setor privado; assim, quando o Estado age de modo direto (empresas estatais) ou indireto (regulação) em campos que lhe são próprios, ou seja, em serviços públicos (art. 175 da Constituição de 1988), onde não se pode falar, na visão do autor, em intervenção; mas em atuação estatal. Aliás, serviço público não é o objeto do trabalho e sim atividade econômica financeira.

Respeitando essa classificação, podemos sistematizar, em conformidade com os artigos da Constituição econômica, que a interferência do Estado no domínio econômico pode ocorrer por três vias: (i) uso do poder normativo e de polícia, conforme o artigo 174 da Constituição de 1988, situação em que o Estado atuará como agente normativo e fiscal das políticas econômicas; (ii) uso de incentivos à iniciativa privada ou setor público, também conforme o artigo 174 da Constituição de 1988, onde o Estado estimula o mercado com incentivos fiscais, financiamentos, compras e obras públicas, prêmios, entre outras medidas, como comumente tem feito em relação aos eletrodomésticos e automóveis e; (iii) uso da via do Estado Empresário para intervir no setor econômico, conforme o artigo 173 da Constituição. Por essa via o Estado, diretamente, por meio de pessoa jurídica que cria, presta atividade econômica. Nessa forma de intervenção existem instrumentos jurídicos que legitimam a propriedade e controle do sistema financeiro pelo Estado, inclusive desapropriando as empresas do setor.

A criação de pessoa jurídica para atuar no setor financeiro não é medida nova. Carvalho ${ }^{72}$ lembra que em 1808, com a chegada de D. João VI ao Brasil, foi criada a primeira versão do Banco do Brasil; em 1861 criava-se a Caixa Econômica que posteriormente se transformaria na Caixa Econômica Federal. De lá para cá surgiram, entre 1933 e 1938 os Institutos de Aposentadoria e Pensões; em 1939, o Instituto de Resseguros do Brasil; em 1943 a Caixa de Crédito Cooperativo que mais tarde se transformaria no Banco Nacional de Crédito Cooperativo; em 1952, o Banco Nacional de Desenvolvimento Econômico e o Banco do Nordeste do Brasil. Todos esses são exemplos de criação de pessoas jurídicas por meio das quais o Estado intervém diretamente no setor financeiro em concorrência com o setor privado.

Entretanto, essa possibilidade garantida pela Constituição de 1988 não permite, por si só, a propriedade integral e a gestão do sistema financeiro pelo Estado brasileiro. Não obstante - Estado crie pessoas jurídicas para atuar de forma direta, ainda existirão instituições privadas atuando no setor; portanto, para a proposta de Avelãs Nunes tornar-se viável, necessário seria o Estado promover a estatização das pessoas jurídicas privadas. O que poderia ocorrer por retomada, encampação e estatização.

A lei 1.803 de agosto de 1860, conhecida como a Lei dos Entraves, lançou as bases para as primeiras estatizações do Brasil. Por meio desse instrumento legal o Estado permutava as ações das companhias a serem estatizadas por títulos públicos, não havendo assim a necessidade de desapropriação. Foi por meio dessa fórmula que o capital acionário da Estrada de Ferro D. Pedro

72 CARVALHO, Ney. A guerra das privatizações. São Paulo: Editora de Cultura. 2009. 
Il se tornou público ${ }^{73}$. Outras encampações ocorreram ao longo da história, Carvalho (2009) cita as encampações das seguintes empresas: Brazil Railway Company e subsidiárias, The Amazon River Steam Navigation Company em 1940; a incorporação das Organizações Henrique Lage, em 1942; a estatização da Cia. Vale do Rio Doce, também na década de 1940, e de diversas refinarias de petróleo, em 1964. Ressalta-se que houve encampação primordialmente em serviços públicos e de algumas atividades econômicas, aos moldes do que ainda é previsto pela Lei 8.987 de 1998, a lei de concessões, em seu artigo $37^{74}$.

Entende-se, entretanto, que o expediente de encampação não é exclusivo para serviços públicos, havendo possibilidade de se valer desse mecanismo para o setor econômico privado e, por consequência, para efetivar a propriedade e gestão do sistema financeiro pelo Estado. Veja-se a previsão do artigo 11, b, do Decreto-Lei nº 2321 de $1987^{75}$, recepcionado pelo artigo $5^{\circ}$, XXIV da Constituição de 1988, que prevê a possibilidade de o Banco Central do Brasil propor a desapropriação, por necessidade ou por utilidade pública ou por interesse social, das ações do capital social da instituição financeira. A competência da expropriação é do Poder Executivo, que deverá depositar o valor indenizatório; ou se apurar que o valor líquido é negativo, depositar mero valor simbólico fixado no decreto expropriatório. Outro exemplo, a Lei nº 4.595 de 31 de dezembro de 1964, que previu expressamente a encampação em seu artigo $47^{76}$ para as emissões de moeda efetuadas pelo Banco do Brasil S/A e da Caixa de Mobilização Bancária. Nota-se, assim, que a encampação já foi utilizada no sistema financeiro, não sendo novidade nos meios jurídicos nacionais, bastaria, para tanto, na atualidade, obedecer aos preceitos constitucionais. Todavia, as estatizações, via desapropriações (expressão jurídica mais apropriada atualmente), devem ser realizadas de forma planejada, afinal, é inconteste que o Estado deva ser responsabilizado por prática de políticas econômicas, ainda que lícitas ${ }^{77}$, quando delas decorrem prejuízos específicos, expressos e demonstrados.

Há, portanto, instrumento jurídico no ordenamento nacional capaz de viabilizar a propriedade integral e a gestão do sistema financeiro: a estatização. Mas, para que o instituto seja aplicado é necessário o respeito aos ditames constitucionais. Haveria, assim, que se verificar se o sistema financeiro privado atua de forma abusiva e/ou bloqueando ${ }^{78}$ os ditames constitucionais, colocando em risco a segurança nacional ou a não efetivação do interesse público. Logo, seria necessário, por exemplo, 73 LEVY, Maria Bárbara. A indústria do Rio de Janeiro através de suas sociedades anônimas. Rio de Janeiro: UFRJ; Secretaria Municipal de Cultura do Rio de Janeiro. 1994, p. 71-88.

74 Diz o artigo 37 da Lei n. 8987 de 28 de setembro de 1998: "Considera-se encampação a retomada do serviço pelo poder concedente durante o prazo da concessão, por motivo de interesse público, mediante lei autorizativa específica e após prévio pagamento da indenização, na forma do artigo anterior".

75 Art. 11. À vista de relatório ou de proposta do conselho diretor, o Banco Central do Brasil poderá: b) propor a desapropriação, por necessidade ou utilidade pública ou por interesse social, das ações do capital social da Instituição.

76 O artigo 47 diz que "será transferida à responsabilidade do tesouro nacional, mediante encampação, sendo definitivamente incorporado ao meio circulante o montante de emissões feitas por solicitação da carteira de redescontos do Banco do Brasil S/A e da Caixa de Mobilização Bancária".

77 SOUZA, Washington Peluso Albino de. Primeiras Linhas de Direito Econômico. $6^{a}$ edição. São Paulo: Editora LTr, $2^{\mathrm{a}}$ tiragem, 2017, p. 125.

78 CLARK, Giovani. CORREAA, Leonardo Alves. NASCIMENTO, Samuel Pontes do. A Constituição Econômica entre a Efetivação e os Bloqueios Institucionais, 2017. 
que as políticas econômicas privadas (por ação ou omissão) do sistema financeiro comprometessem o desenvolvimento da nação fragilizando os direitos fundamentais; ou inviabilizassem a soberania econômica nacional praticando abusos do poder econômico por cercear a concorrência no setor; ou, então, construindo cartéis para dilatar seus ganhos e, assim, subjugar consumidores, empresas e entes públicos endividados. Deve, pois, o Estado intervir no sistema financeiro a fim de dar concretude a constituição de 1988, mas sempre adequando os fins almejados aos meios utilizados, tendo em mira a linha de maior vantagem ${ }^{79}$.

Ademais, o artigo 50, XXIV da Constituição de 1988 faculta ao Estado poderes gerais de desapropriação, conforme a lei, mediante pagamento de justa e prévia indenização em dinheiro, nos casos de necessidade ou utilidade pública ou por interesse social. Assim, a União, por exemplo, a fim de dar materialização à nossa Lei Maior, sobretudo aos comandos da Constituição Econômica, visando o fim do abuso do poder econômico que solapa o mercado interno e a soberania econômica nacional, poderia desapropriar o setor financeiro parcial ou totalmente pelos comandos do DecretoLei nº 2.321 de 1987, recepcionado pela Constituição de 1988 como Lei Complementar. Reforçando os nossos argumentos, o artigo 174, caput, da Constituição de 1988, fixa o poder estatal de normatizar e fiscalizar as atividades econômicas, incluindo as financeiras, no intuito de materializar os artigos 170 e 192 da Constituição. A segunda pergunta proposta também tem resposta afirmativa: a encampação/ desapropriação seriam os instrumentos jurídicos constitucionais previstos no ordenamento brasileiro vigente que possibilitariam a propriedade integral e gestão do sistema financeiro por parte do Estado.

\section{CONSIDERAÇÕES FINAIS}

O modo operante anterior, desenho institucional possível no pós II-Guerra Mundial, se equilibrou entre dois polos. De um lado as demandas democráticas por materialização de direitos e, do outro, as demandas do setor financeiro por mais lucros e liberdade de ação. Com o fim das políticas keynesianas, nos anos 1970, e a captura do poder político pelo poder financeiro, via dívida pública, as políticas democráticas de concretização de direitos têm sido constantemente ignoradas.

O adiamento da concretização constitucional, decorrência da inversão da fórmula regulatória do Mercado proporcionou a instituição de um Estado sob a vigilância do Mercado em vez do Mercado sob a Vigilância do Estado. Diversas são as constatações empíricas desse domínio financeiro sobre as esferas de decisões estatais no Brasil: privatizações e adoção do modelo regulador na década de 1990; primarização e financeirização da economia desde a década de 1990 até a atualidade e; adoção, em 2016, do teto dos gastos públicos - Novo Regime Fiscal -, suspendendo a concretização de direitos constitucionais por vinte anos, mas mantendo intacta a parcela orçamentária destinada ao setor financeiro. Esse movimento de financeirização estabeleceu, no capitalismo moderno, a permanência da crise e constantes tensões sociais.

79 SOUZA, Washington Peluso Albino de. Teoria da Constituição Econômica, 2002. 
A crise, por si só, não representa um momento negativo e sim a oportunidade de se verificar a (in)eficácia do sistema e de se propor algo novo. A crise do sistema financeiro de 2008, em muitas nações, levou estadistas e estudiosos a estabelecerem um conjunto de políticas econômicas e medidas para conter os estragos causados no chamado capitalismo financeiro. Entende-se, entretanto, que nenhuma das medidas pode ser vista como proposta estrangeira ao próprio sistema.

À questão proposta como guia do ensaio, a de que se o Estado pode ser, ou não, juridicamente, proprietário e gestor do sistema financeiro no Brasil sem ferir o Texto Constitucional de 1988, resultou em resposta afirmativa.

Tudo ponderado, apontamos ser viável e constitucional, no Brasil, a aplicação da proposta de Avelãs Nunes de tornar o Estado proprietário e gestor do sistema financeiro. Afinal, a Constituição de 1988 não adota uma única ideologia política podendo, assim, via a intervenção estatal no sistema financeiro por meio da encampação/desapropriação, o controle total e direto do setor financeiro. Mas, para proposta ser levada a efeito, seria necessário, além do cumprimento dos ditames constitucionais e legais, a demonstração que as políticas econômicas (ações e omissões) do setor financeiro privado, de alguma forma, obstruíram, violaram ou bloquearam os comandos da constituição brasileira inviabilizando o interesse público de concretização constitucional.

Embora a reflexão aqui produzida tem a importância de apontar luzes jurídicas e fomentar debates sobre as possibilidades reais de, no Brasil, a propriedade e gestão do sistema financeiro passar a ser do Estado, sem dados empíricos ou projeções matemáticas não é possível afirmar ser essa, a da estatização do setor financeiro, a única solução para os problemas estruturais e de atraso quanto ao desenvolvimento capitalista brasileiro. O desenvolvimento tardio depende, também, da integração dos setores produtivos, industrialização e complexidade tecnológica, ladeando Estado e Mercado, a exemplo, do que outros países capitalistas avançados implementaram em suas políticas econômicas.

Dentre os dois polos de ação, o de concretização de direitos e o de favorecimento do setor financeiro, a estrutura econômica vigente, embora constitucionalmente prevista em favor da concretização de direitos, tende à atender as demandas do setor financeiro. Tal opção tem relegado o Brasil à secular posição periférica no capitalismo global. Ciente das possibilidades constitucionais, de planejar, projetar, controlar e gerir o sistema produtivo e financeiro, esperamos ter contribuído para a concepção de que o Estado é importante ator econômico. Assim, enquanto ator econômico, o Estado é também senhor de seu devir histórico não devendo, portanto, se sujeitar às ilusões financistas que até o presente momento não se justificaram como alternativa ao desenvolvimento tardio. 


\section{REFERÊNCIAS DAS FONTES CITADAS}

AVELÃS NUNES, António José. As duas últimas máscaras do Estado capitalista. Pensar. Fortaleza. v. 16, n. 2, p.409-476, jul/dez 2011.

AVELÃS NUNES, António José. Breve reflexão sobre o chamado estado regulador. Revista Sequência. $n^{\circ}$. 54, p. 9-18, jul. 2007.

BANDEIRA DE MELLO, Celso Antônio. Curso de Direito Administrativo. 26ª ed. Editora Malheiros: São Paulo. 2009.

BELTRÁN, Enrique Navarro. La Constitución Económica Chilena Ante Los Tribunales de Justicia. Providencia: Universidad Finis Terrae, 2016.

BERCOVICl, Gilberto. Direito Econômico do Petróleo e dos Recursos Minerais. São Paulo: Quartier Latin, 2011.

BERCOVICl, Gilberto; MASSONETTO, Luís Fernando. A Constituição dirigente invertida: a blindagem da Constituição Financeira e a agonia da Constituição Económica. Boletim de Ciências Económica. Faculdade de Direito da Universidade de Coimbra, vol. XLIX, p.57-77, 2006.

BERCOVICl, Gilberto. Constituição econômica e desenvolvimento: uma leitura a partir da Constituição de 1988. São Paulo: Malheiros, 2005.

BERCOVICl, Gilberto. O princípio da subsidiariedade e o autoritarismo. Consultor Jurídico. Disponível em: www.conjur.com.br/2015-nov-08/estado-economia-principio-subsidiariedade-autoritarismo. acesso em 29 de março de 2018.

BOITO JR, Armando. BERRINGER, Tatiana. Classes Sociais, Neodesenvolvimentismo e Política Externa nos Governos Lula e Dilma. Revista de Sociologia e Política. v. 21, n. 47, set. 2013, p. 31-38.

BOLÍVIA. Declaración Constitucional Plurinacional 02/2013, 19 de abril de 2013. Diposnível em: http://www. tcpbolivia.bo/tcp/content/declaraci\%C3\%B3n-constitucional-plurinacional-022013-19-de-abril-de-2013.

Acesso em 18 de abril de 2018.

BRASIL, Constituição da República Federativa do Brasil de 1988. Disponível em: http://www.planalto.gov. br/ccivil_03/constituicao/constituicao.htm. acesso em 06 de maio de 2013.

BRASIL. Ação Direito de Inconstitucionalidade 1950-SP. Brasília: Supremo Tribunal Federal, 2005.

CANOTILHO, J. J. Gomes. O Estado garantidor: claros-escuros de um conceito. In AVELÃS NUNES, António José; COUTINHO, J. N. Miranda (Org.). O Direito e o futuro: o futuro do direito. Coimbra: Almedina, 2008.

CARVALHO, Ney. A guerra das privatizações. São Paulo: Editora de Cultura. 2009.

CLARK, Giovani. O neoliberalismo de regulação como intervenção do Estado - A regulação e a Constituição de 1988. Lisboa: Lusíada: Economia \& Empresa, n. 9, 2009.

CLARK, Giovani. O pioneirismo da Faculdade de Direito da UFMG: a introdução do Direito Econômico no Brasil. Revista Brasileira de Estudos Políticos. Belo Horizonte. n. 40, ano 2012, p. 143-155.

CLARK, Giovani; CÔRREA, Leonardo Alves; NASCIMENTO, Samuel Pontes do. Ideologia constitucional e pluralismo produtivo. Revista da Faculdade de Direito da UFMG: número especial em memória do Professor Washington Peluso Albino de Souza, ano 2013, p. 265-300.

CLARK, Giovani. CORRÊA, Leonardo Alves. NASCIMENTO, Samuel Pontes do. A Constituição Econômica entre a Efetivação e os Bloqueios Institucionais. Revista da Faculdade de Direito da Universidade Federal de Minas Gerais, n, 71, jul/dez 2017, p. 677-700. 
CRUZ, Paulo Márcio. A crise financeira mundial, o Estado e a Democracia econômica in Revista Pensar. Fortaleza. Disponível em: http://hp.unifor.br/pdfs_notitia/3364.pdf, acesso em 07 de maio de 2013.

DOWLING, Emma. After Austerity: Social Impact Bonds and the financialisation of the welfare state in Britain. New Politcal Economy. Setember, 2016.

EUROPEAN SYSTEMIC RISK BOARD - ESRB. Mission, objectives and tasks. Disponível em: http://www.esrb. europa.eu/about/tasks/html/index.en.html. Acesso em: 10 de maio de 2013.

FOUCAULT, Michael. Nascimento da Biopolítica. Martins Fontes: São Paulo, 2008.

GRAU, Eros Roberto. A ordem econômica na constituição de 1988. 14. ed. São Paulo: Malheiros, 2010.

GRAU, Eros Roberto. Voto do relator. Ação Direita de Inconstitucionalidade 1950-SP. Brasília:Supremo Tribunal Federal, 2005.

HUTTON, Will. Podemos desfazer a privatização. E não nos custará um centavo. Disponível em: https:// jornalggn.com.br/noticia/britanicos-querem-reestatizar-empresas. Acesso em 10 de março de 2018.

JUSTEN FILHO, Marçal. Curso de Direito Administrativo. Ed. Saraiva. São Paulo. 2005.

LAROSIĖRE, Jacques de. et al. The High Level Group on Financial Supervisor in the EU. Bruxelas, 2009. Disponível em: http://ec.europa.eu/internal_market/finances/docs/de_larosiere_report_en.pdf, acesso em 10 de maio de 2013.

LELIS, Davi Augusto Santana de. Ensaios sobre a atuação estatal. Rio de Janeiro: Lumen Juris. 2019.

LELIS, Davi Augusto Santana de; COSTA, Lorena Vieira. Julgamento moral, economia e políticas públicas. Revista de Presidência. V. 18, n. 114. 2016.

LELIS, Davi Augusto Santana de. Direitos sem dinheiro: do Novo Regime Fiscal à COVID-19. Ciências Sociais Unisinos. São Leopoldo. Vol. 56, N. 2. P. 164-176, maio/ago. 2020.

LEVY, Maria Bárbara. A indústria do Rio de Janeiro através de suas sociedades anônimas. Rio de Janeiro: UFRJ; Secretaria Municipal de Cultura do Rio de Janeiro. 1994.

MAGALHÃES, José Luiz Quadros. Direito Constitucional: curso de direitos fundamentais. $3^{a}$ ed. São Paulo: Método. 2008.

MOREIRA, Vital; MAÇÃS, Fernanda. Autoridades Reguladoras Independentes, estudo e projecto de leiquadro. Coimbra: Coimbra Editora, 2003.

RICOUER, Paul. Interpretação e ideologia. $4^{a}$ ed. Rio de Janeiro: Francisco Alves. 1990.

SALGADO, Joaquim Carlos. O Estado ético e o Estado poiético. Revista do Tribunal de Contas de Minas Gerais, Belo Horizonte, v.27, n.2, abr/jun, 1998.

SILVA, José Afonso da. Comentário Contextual à Constituição. 6º edição. São Paulo: Malheiros, 2009.

SILVA, Paula Costa; PAÇÃO, Jorge. A encruzilhada da supervisão das instituições de crédito. In Revista da Procuradoria-Geral do Banco Central. Volume 6. Número 2. dezembro de 2012. p.91-111. Brasília:BCB, 2012.

SOUZA, Jessé. A tolice da inteligência brasileira: ou como o país se deixa manipular pela elite. São Paulo, Leya, 2015.

SOUZA, Júlia Gomes e. Crise do neoliberalismo e seus reflexos no aparelho estatal: apontamentos para a reflexão do caso boliviano. Disponível em: http://www.ifch.unicamp.br/formulario_cemarx/selecao/2009/ trabalhos/crise-do-neoliberalismo-e-seus-reflexos-no-aparelho-estatal.pdf. Acesso em 17 de maio de 2013. 
Novos Estudos Jurídicos

SOUZA, Washington Peluso Albino de. Conflitos Ideológicos na Constituição Econômica. Revista Brasileira de Estudos Políticos. Belo Horizonte, Universidade Federal de Minas Gerais n. 74-75, jan-jul. 1992.

SOUZA, Washington Peluso Albino de. O princípio da ambiguidade na configuração legal da ordem 'econômica'. Revista da Faculdade de Direito da UFMG, n.21(13), 1956.

SOUZA, Washington Peluso Albino de. Teoria da Constituição Econômica. Belo Horizonte: Del Rey, 2002.

SOUZA, Washington Peluso Albino de. Primeiras Linhas de Direito Econômico. $6^{a}$ edição. São Paulo: Editora LTr, $2^{\text {a }}$ tiragem, 2017.

WIGGAN, Jay. Policy Boostering the Social Impact Investment Market in the UK. Jnl Soc. Pol. Cambridge University Press. (2018), 47, 4, 721-738. 2018.

Recebido em: 13/04/2020

Aprovado em: 28/09/2020

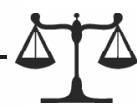

